\title{
Measuring labor input on pasture-based dairy farms using a smartphone
}

\author{
J. Deming, ${ }^{*} \dagger^{1}$ D. Gleeson, ${ }^{*}$ T. O’Dwyer, ${ }^{*}$ J. Kinsella,† and B. O’Brien* \\ *Teagasc, Animal \& Grassland Research and Innovation Centre, Moorepark, Fermoy, Co. Cork, P61 C997 Ireland \\ †School of Agriculture and Food Science, University College Dublin, Belfield, Co. Dublin, D07 YH5R Ireland
}

\section{ABSTRACT}

With the cessation of milk quotas in the European Union, dairy herd sizes increased in some countries, including Ireland, with an associated increase in labor requirement. Second to feed costs, labor has been identified as one of the highest costs on pasture-based dairy farms. Compared with other European Union countries, Ireland has historically had low milk production per labor unit; thus, optimization of labor efficiency on farm should be addressed before or concurrently with herd expansion. The objective of this study was to quantify current levels of labor input and labor efficiency on commercial pasture-based dairy farms and to identify the facilities and management practices associated with increased labor efficiency. Thirty-eight dairy farms of varying herd sizes, previously identified as labor-efficient farms, were enrolled on the study and data were collected over 3 consecutive days each month over a 12-mo period, starting in May 2015 and finishing in August of 2016. This was achieved through the use of a smartphone application. For analysis purposes, farms were categorized into 1 of 3 herd size categories (HSC): farms with <150 cows (HSC 1), 150-249 cows (HSC 2), or $\geq 250$ cows (HSC 3). Overall farm labor input increased with $\mathrm{HSC}$ with 3,015, 4,499, and 6,023 $\mathrm{h}$ worked on HSC 1, 2, and 3, respectively. A higher proportion of work was carried out by hired staff as herd size increased. Labor efficiency was measured as total hours input to the dairy enterprise divided by herd size. Labor efficiency improved as herd size increased above 250 cows with $17.3 \mathrm{~h} /$ cow per yr observed for HSC 3; labor efficiency was similar for HSC 1 and 2 , at 23.8 and $23.3 \mathrm{~h} / \mathrm{cow}$ per yr, respectively. A large range of efficiency was observed within HSC. The labor requirements had a distinct seasonal pattern across the $3 \mathrm{HSC}$ with the highest input observed in springtime (February to April) primarily due to calving

\footnotetext{
Received December 14, 2017.

Accepted May 29, 2018.

${ }^{1}$ Corresponding author: justine.deming@teagasc.ie
}

and calf-care duties, milking, and winter feeding. The lowest input was observed in wintertime (November to January) when cows were dry. Particular facilities and management practices were associated with efficiency within certain tasks, the most notable in regard to milking and winter feeding practices. Additionally, the most efficient farms used contractors to perform a higher proportion of machinery work on farm than the least efficient farms.

Key words: dairy farm labor, labor efficiency, hours per year, pasture-based

\section{INTRODUCTION}

Unique within the predominantly indoor systems of the European dairy industry, the Irish dairy sector is characterized by a seasonal pasture-based system with enterprises that rely heavily on family labor (Boyle, 2002). Optimizing the utilization of pasture is one of the key aspects to increased overall farm profitability in pasture-based dairy systems such as those found in Ireland, Australia, and New Zealand. However, labor is now seen as an increasing cost in these systems. As herd size increases, associated increases occur in the number of both part-time and full-time staff (Gleeson et al., 2007; O'Donovan et al., 2008). Reports from the Farm Accountancy Data Network (FADN, 2016) indicated that in 2013, $88 \%$ of labor on Irish dairy farms consisted of family labor. However, dairy herd size has increased following the abolition of the quota system in the European Union, and the number of Irish dairy farms with herds greater than 100 cows has increased from $4.5 \%$ of all Irish dairy farms in 2005 to $23 \%$ in 2016 (Teagasc, 2017).

While the average herd size in Ireland was 76 cows in 2016, it was relatively small compared with an average herd size of 419 cows in 2015/2016 in the New Zealand pasture-based system and an average herd size of 262 cows in Australia in 2016/2017 (DairyNZ and LIC, 2016; Dairy Australia, 2017; Teagasc, 2017). However, the Irish pasture-based dairy industry is undergoing a transformation similar to the change witnessed on farms in those countries since the 1990s. From 1990, 
a dramatic shift has occurred in the number of dairy farms with a decrease of 18 and $60 \%$ in Australia and New Zealand, respectively, with herd size increasing by 160\% (Dairy Australia, 2015; DairyNZ and LIC, 2015).

The Central Statistics Office of Ireland (CSO; Ireland's national statistical office whose purpose is to impartially collect, analyze, and make available statistics about Ireland's people, society, and economy) defines an annual working unit (AWU) or full-time staff as someone working $1,800 \mathrm{~h} / \mathrm{yr}$. Of the different sectors of agricultural work in Ireland (dairy, beef, arable, sheep, or mixed enterprises), specialist dairying is the most labor-intensive farm type with $84 \%$ of farm owners working at least 1.0 full AWU in 2013, and 94.9\% working at least 0.75 AWU. In contrast, just $12.7 \%$ of farm owners in other farm sectors worked 0.75 AWU or more (CSO, 2013). The seasonality of farm labor requirements within spring-calving pasture-based systems is central to the understanding of labor demands in these systems. The tasks of calving and calf rearing require significant labor resources in the spring time (February-April in the Northern Hemisphere), making this the busiest time of year (Gleeson et al., 2007; O'Donovan, 2008). It is well-documented that the milking task accounts for the majority of labor required on pasture-based dairy farms with reports of it accounting for 40 to $50 \%$ of total farm labor in Australia and $34 \%$ in Ireland (Mein and Smolenaars, 2001; O'Donovan et al., 2008). Thus, optimizing labor-efficient practices and facilities for these tasks is of key importance when considering an increase in herd size and the associated labor increases.

According to the 2015 Irish National Farm Survey, $34 \%$ of dairy farms (319 sampled) were managing at least 74 cows per AWU (NFS, 2016). The last labor study undertaken in Ireland related to dairying revealed an estimated labor requirement of $41.3 \mathrm{~h} / \mathrm{cow}$ per yr for an average herd size of 77.4 cows (O'Donovan et al., 2008). This was an improvement from the 53.8 $\mathrm{h} /$ cow per yr found in an earlier labor study of Irish dairy farms with a similar average herd size (O'Shea et al., 1988). However, upon comparison with the pasturebased system in New Zealand, the Irish $41.3 \mathrm{~h} /$ cow per yr was at a lower labor efficiency level than the $20 \mathrm{~h} /$ cow per yr for a much larger herd of 229 cows in New Zealand herds (IFCN, 2002). New Zealand has increasingly turned to technology as a means of circumnavigating the labor issue to improve labor productivity with a particular focus on the milking tasks, which has shown an improvement in labor efficiency and profitability (Jago et al., 2010; Edwards et al., 2013a, 2015; Eastwood and Yule, 2015). Therefore, the Irish system has opportunities to identify and implement more ef- ficient practices to reduce the amount of labor inputted per cow.

A strong link is present between increased scale of enterprise and increased labor efficiency (O'Donovan, 2008; Deming et al., 2015). As dairy herd size increases, the farm business operation increases in similarity to other business models (e.g., requirement for semiskilled, skilled, and managerial personnel). With the addition of more staff on farm, farmers will need to adopt new skills such as human resource management.

In conjunction with improving labor productivity and efficiency is the need to improve the image of dairy farming as an occupation. Historically, labor shortages and the difficulty of finding qualified personnel have been a struggle for dairy farmers (Winsten et al., 2010). Similar to the challenges with hired staff in Ireland, New Zealand farmers reported recruitment and retention of skilled employees as a challenge to their businesses with $40 \%$ of farmers reporting difficulty in recruitment at all skill levels (Eastwood et al., 2015). Myles (2000) previously reported the difficulty in retaining good farm staff in a sector where young farm workers described poor working conditions, labor management issues, and the absence of career progression. Other aspects of the industry that have resulted in a negative image are the long days, unusual working hours, and repetitious work associated with the milking task, which frames the working day with early morning starts and late finish times to accommodate a balanced milking interval (Porter, 1993). Farm owners and workers are putting a greater emphasis on work/life balance, which can be managed through improved labor efficiency, the addition of help on farm, or both (Macken-Walsh and Byrne, 2015).

Thus, it is crucially important to first generate factual data on the overall labor supply and demand issue on farms, and second, once the scale of the problem is observed, potential solutions can be put forward. It may be possible to reduce labor demand on farms through improving operational strategies, facilities, introduction of technology, or improved management of people and tasks on the farm. But the central point is that the labor must first be measured.

To address the issue of increased herd size and need for increased efficiency and productivity, current labor demand and efficiency must be quantified. Knowing the time required for different tasks, identification of opportunities for improvement through technology and the orientation of research and development to automating and streamlining tasks is of considerable importance. Thus, the objective of this study was to quantify levels of labor input and labor efficiency on commercial labor-efficient dairy farms and to identify 
Table 1. Descriptive statistics of farms in the data sets and within each herd size category (HSC) ${ }^{1}$

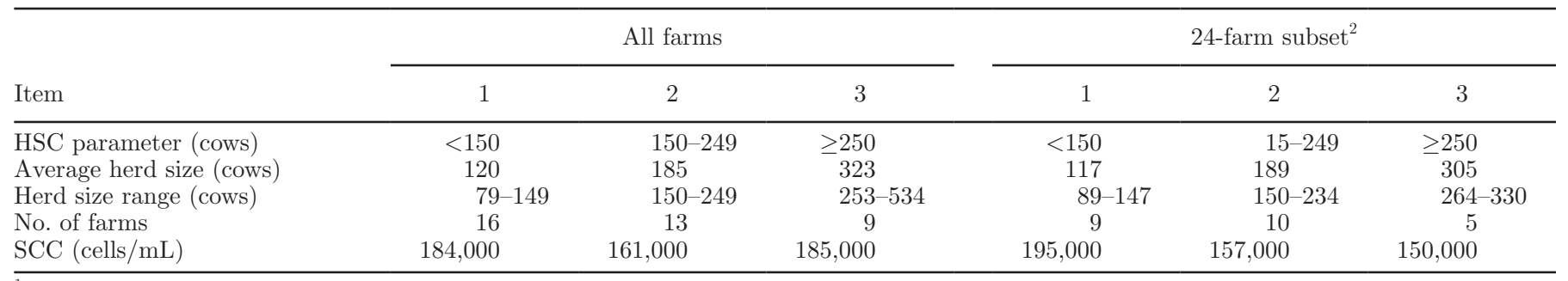

${ }^{1} 1$ = farms with $<150$ cows; 2 = farms with 150 to 249 cows; and $3=$ farms with $\geq 250$ cows.

${ }^{2}$ Subset of 24 farms that had a full 12 mo of data collection.

the facilities and management practices associated with increased labor efficiency.

\section{MATERIALS AND METHODS}

\section{Farmer Selection}

Farmers were selected for this study based on the following criteria: spring-calving dairy farms with dairy as the primary enterprise $(>70 \%$ livestock being dairy cows), herd size ranging between 60 and 600 cows, as well as the farmer being an owner and user of a smartphone and an active participant in farmer discussion groups working with Teagasc (The Irish Agriculture and Food Development Authority).

According to the Central Statistics Office, in 2014 the average Irish dairy herd size was approximately 60 cows, and given that herd sizes were expected to increase nationally following quota abolition in April 2015, it was decided to limit the farms on the study to those with the average herd size as a minimum. The decision to limit the maximum herd size to 600 cows was a consequence of the fact that herds greater than this size were very uncommon in Ireland $(0.07 \%$ of all herds), which would make it difficult to draw conclusions from the study. The decision to select discussion group participants was justified by the interest required for the long-term data recording process and that labor efficient farms were required. We expected that discussion group members would be more familiar and reliable at data recording and also more labor efficient than nondiscussion group members. Literature shows that advisory services, such as these discussion groups, can facilitate innovations in agriculture at the farm level (European Commission, 2010; Rivera, 2011; Faure et al., 2012). Additionally, it has been documented that those who specialize in dairying (as opposed to multiple enterprises) and use business support mechanisms (such as paying for independent technical advice) have improved labor efficiency and profitability (Wilson, 2011). It was decided that only farms deemed highly labor efficient would be selected as the goal was to identify best practices to streamline labor efficiency, not to highlight practices that were inefficient. Over 40 Teagasc dairy advisors from across the country were contacted and asked to nominate farms that they deemed as highly labor-efficient and to communicate contact details to the researcher conducting the study. One hundred fourteen farms were suggested by the 26 advisers who responded. Contact was made through phone calls to the nominated farmers, the project was explained, and participation was requested. Of these farmers, 45 fit the aforementioned criteria and agreed to participate. The farms were then visited by the researcher and a technical support assistant to demonstrate to the farmers and staff, where applicable, how to use the smartphone application (app) that was developed to track labor input on farms (see next section for details). Thirtyeight farms remained on the study over the entire duration of the 12- to 15 -mo period. Farms were asked to participate for up to 15 mo to allow for acclimation to the app. Farms were removed from the study where the data entry was not being completed properly each month. Descriptive data on the participating farms are shown in Table 1.

\section{The Smartphone Application}

The required features of the app were identified and it was developed by an external company specialized in digital data collection (Acorn Agricultural Research, Cork, Ireland). The design of the app allowed farmers to record labor data in real-time by starting and stopping the app's stopwatch as each designated task was commenced and completed. Each farmer used the app on their smartphone to record their own personal labor data. Employees or family members who provided farm labor and had their own smartphone were also able to use the app to record their labor input. Seventeen percent of all farm staff (part-time and full-time) used the app. This number was low because most staff on this study were casual, part-time employees who worked on the farms for a brief period during the spring. People using the app were asked to record their labor data for 
3 consecutive days (the last Tuesday, Wednesday, and Thursday of each month) for between 12 and 15 mo to capture all seasons and to allow for adaptation to using the app. For some farmers, the initial 1 to 2 mo of data had to be removed from the data set because the data were not sufficiently complete for proper interpretation. Consequently, those farmers collected data for up to 15 mo. We chose to record on the same 3 weekdays to capture regular farm activity and for consistency for the farmers each month. Twenty-nine tasks were listed in alphabetical order on the app that the farmers could choose from at any given time (Table 2). When the app user wished to start a task they pressed the selected task "Start" button, at which point the timer would start recording. When the task was complete the app user pressed the "Stop" button. Using the app allowed us to gain data on actual start and finish times of tasks throughout the day. Upon the first meeting with farmers, it was stressed that real-time data collection was most desirable. It was possible for users to input data retrospectively, but this was discouraged unless it was absolutely necessary. As app users entered their task data throughout the collection periods, data were automatically sent to the cloud database. If the phone was outside of $3 \mathrm{G}, 4 \mathrm{G}$, or Wi-Fi coverage, the app would continue to work and would send the data to the cloud when it returned to Internet coverage.

\section{Monthly Survey}

To capture other labor contributions on the farm, a short online survey was implemented, which farmers completed once per month. At the end of the 3 smartphone data collection days, each farmer received an automated text message requesting them to complete an online survey and received a reminder text message every day until the online survey was completed. In this survey, farmers were asked to complete labor data for any part-time or full-time $(1,800 \mathrm{~h} / \mathrm{yr}$ ) labor (family or hired) that worked on the farm during the 3 data collection days, and whose data were not already collected via the app. Farmers were also asked to input stock data and to indicate hours of machinery work (machinery tasks can be found in Table 3) conducted on farm for the entire month using either their own equipment or the services of a contractor.

\section{Additional Information}

A one-off phone survey was conducted with each farmer regarding their farm facilities and practices. The researcher phoned each farmer in December 2015 and completed a questionnaire. Questions were split
Table 2. Tasks listed on the smartphone app

- advisory

- AI (artificial insemination)

- breaks

- calf care/feeding

- calving tasks

- cleaning yards

- cubicle cleaning

- driving jeep/car

- drying off

- feeding cows and heifers

- fertilizer spreading

- grass measurement

- heat observation

- herding post-milking

- herding pre-milking

- land and building maintenance

- machinery maintenance

- milking

- office/business

- other dairy tasks

- other enterprise tasks

- silage pit management

- slurry spreading

- soiled water spreading

- strip fencing

- topping

- trading stock

- veterinary

- washing post-milking

into the main categories of winter housing, grassland management, the milking process, breeding, and calves; responses were inputted directly into an Excel (Microsoft Corp., Redmond, WA) spreadsheet.

Bulk tank milk SCC is a widely accepted indicator of udder health status within a herd (van Schaik et al., 2002; Schukken et al., 2003). Therefore, monthly production and SCC information was collected retrospectively from the Irish Cattle Breeding Federation to determine if an association was present between labor efficiency and milk quality and production.

Table 3. Machinery tasks inputted to the monthly online survey

- winter feeding

- fertilizer spreading

- topping

- slurry spreading

- soiled water spreading

- agitating

- reseeding

- pit silage

- baled silage

- spraying

- farm yard manure spreading

- hedge cutting

- lime spreading

- digger work

- other 
Table 4. Grouping of tasks

\begin{tabular}{ll}
\hline Calf care & Calf care/feeding and calving tasks \\
Cow care & Baled silage, feeding cows and heifers, pit silage, and winter feeding \\
Cleaning & Cleaning yards and cubicle cleaning \\
Grassland & Agitating, fertilizer spreading, farmyard manure spreading, grass measurement, slurry spreading, soiled water \\
& spreading, spraying, strip fencing, and topping \\
Maintenance & Digger work, hedge cutting, lime spreading, reseeding, and machinery maintenance \\
Management & Advisory, office/business, and trading stock \\
Milking & Herding premilking, milking, herding postmilking, and washing postmilking \\
Miscellaneous & Other (machinery related), driving jeep/car, and other dairy tasks \\
Veterinary & Veterinary, drying off, heat observation, and AI
\end{tabular}

\section{Data Checking and Adjustments}

Data collection commenced in May 2015 and were completed in August 2016 at which point it was prepared for analysis. The monthly data from the app and the monthly survey data were compiled and checked for errors. Problems such as duplicate entries, overlapping entries, and task duration (too short or too long) were checked and corrected where necessary by the researcher. Data were also cleaned for time spent at "breaks" and "other enterprise tasks" (other than dairy) and these data were removed from the data set. Similar checks were carried out on the information from the online monthly survey. The time data associated with the tasks of "fertilizer spreading," "pit silage," "slurry spreading," "soiled water spreading," and "topping" were taken from the monthly survey rather than the app, as this was considered more accurate than the information for these tasks in the 3-d data collected period as these represented tasks carried out intermittently over the full month. The 29 tasks related to the labor input (Table 2) by either the app or the monthly survey, along with the 15 tasks from the machinery work portion of the survey (Table 3 ), were consolidated and grouped for summarization (Table 4).

\section{Calculations}

Throughout the duration of the study, the app users inputted their labor task data in real time for 3 consecutive days each month. Three days of data entry were chosen as it was also used in O'Donovan (2008) and also in Shortall et al. (2016). The average monthly labor input by the farmers per task was obtained by adding the task duration for each day within the $3 \mathrm{~d}$ of data collection and dividing by the number of days the user used the app in that month (app users were asked to record all $3 \mathrm{~d}$, but that did not always occur). The total duration of the tasks was then summed (creating an average over the days of data input via the app) and multiplied by the total number of days for that calendar month less number of Sundays for that month. This calculation is based on the premise that farmers work 5 full days throughout the week and 2 half days over the weekends, performing only the necessary tasks such as milking and feeding (O'Donovan, 2008). With regard to work carried out by part-time family members or employees, each farmer was asked to give their best estimations of hours worked per month by those individuals. Hours worked per year was calculated by summing the hours worked by each individual on the farm plus the hours of contractor work performed each month. Labor efficiency was measured as hours per cow per year (h/cow per yr). Cow numbers (both dry and milking) were collected via the online monthly survey and an average was taken over the year. Other studies have analyzed labor data based on herd size or liters of milk produced (inferred herd size) with hours/cow per year as their measure of efficiency (O'Shea et al., 1988; McNab and Meek, 1991; O'Donovan et al., 2008; Wilson, 2011).

Farms were assigned to 1 of 3 herd size categories (HSC) for analysis. These categories were based primarily on average number of cows, but the necessity of hired staff was also considered when creating the herd size limits. According to the Central Statistics Office of Ireland, staff are considered to be full-time if they work 1,800 h/yr. Herd size categories 1 was based on herds with $<150$ cows and in which hired staff would probably account for $<0.5$ of a full-time staff member, HSC 2 was based on herds with 150 to 249 cows and hired staff would probably count for $>0.5$ of a full-time staff member, and finally, HSC 3 was based on herds with $\geq 250$ cows where hired staff would likely consist of $\geq 1$ full-time staff member. Thus, the HSC were based on the herd sizes and the approximate amount of labor needed to run those farms, but the final decision on which farms were assigned to which HSC was based solely on their average herd size.

To determine the main differences between the most labor efficient and least labor efficient farms, a subset of 24 farms that had a full 12 mo of both app data and monthly survey data were examined. This subset was also used when looking into seasonal variation in labor. Seasons were defined as spring (February 1-April 30), summer (May 1-July 31), autumn (August 1-October 
31), and winter (November 1-January 31). The farms were ranked on overall farm labor efficiency and the $25 \%$ most efficient $(\mathrm{n}=6)$ and $25 \%$ least efficient (n $=6$ ) farms were analyzed on an hours per cow basis on a group task basis and then on an individual task basis. Furthermore, the tasks of milking, cow care, and machinery work were examined with regard to facilities and practices within these most and least efficient groups. The examination of the calf care/feeding task focused on the most and least efficient farms (based on $\mathrm{h} /$ cow per yr of the calf care/feeding task) of all farms from the data set who reared calves at home $(\mathrm{n}=30)$. Results presented relate to the entire data set unless stated otherwise.

\section{Statistical Analysis}

Statistical analyses were conducted using SAS software (version 9.1, SAS Institute Inc., Cary, NC). Least squares means among categories were calculated for variables using linear models in PROC MIXED and PROC GLM procedures of SAS. Tukey's test for multiple comparisons was used and statistical differences were considered significant using a 0.05 significance level. Residual checks were made to ensure the assumptions of the analysis were met. Where appropriate, for data that were not normally distributed, the natural log-transformation was used and back-transformed results are presented.

\section{Disclaimer}

Preliminary results from this data set were presented at the XXXVII Commission Internationale del'Organisation Scientifique du Travalen Agriculture (CIOSTA) and Commission Internationale du Génie Rural (CIGR) conference in 2017 and published in the associated journal (Deming et al., 2017). The results from this publication were from a preliminary analysis, the results of which have changed slightly in the current analysis. Results were limited to hours worked in the different HSC, level of efficiencies, seasonal labor input, proportion of labor conducted by different members on farm, and the farmer start and finish times. The current manuscript covers a more in-depth analysis of this data set and delves further into the discussion and implications of the study.

\section{RESULTS}

\section{On-Farm Labor Input}

Average total farm labor input was 4,512 h/yr across all farms with an average herd size of 187 cows. This resulted in an average farm labor efficiency level of 22.2 $\mathrm{h} /$ cow per yr. Total farm hours increased but labor efficiency improved as HSC increased. Labor efficiency varied substantially within HSC with a range of 12.6 $\mathrm{h} /$ cow per yr to $38.9 \mathrm{~h} /$ cow per yr in HSC $1 ; 13.9 \mathrm{~h} /$ cow per yr to $33.7 \mathrm{~h} /$ cow per yr in HSC 2; and $12.9 \mathrm{~h} /$ cow per yr to $22.7 \mathrm{~h} /$ cow per yr in HSC 3 . The average contributions of labor sources across HSC can also be seen in Table 5 and Figure 1. Hours worked by the farmer was similar across HSC; however, the farmer performed 74,54 , and $35 \%$ of the total farm work in HSC 1, HSC 2, and HSC 3, respectively. The remaining hours were filled by hired staff, family labor, and contractor work (machinery tasks). Total hours worked by the family and the contractors were similar across HSC with the proportions of each increasing as HSC increased. A larger proportion of overall labor was also contributed by hired staff in HSC $3(2,348 \mathrm{~h} / \mathrm{yr})$ at an average of 1.30 full-time staff compared with HSC 1 or 2 , which had 0.14 and 0.73 full-time staff, respectively.

"Milking" represented $33 \%$ of total annual farm labor (h/cow per yr) across all herds. This task group was followed by "cow care" at $17 \%$ where the majority of time was attributed to winter feeding of cows and heif-

Table 5. Overall labor input $( \pm \mathrm{SE})$ on farm across herd sizes and contributions $(\mathrm{h} / \mathrm{cow}$ per yr) to the milking task

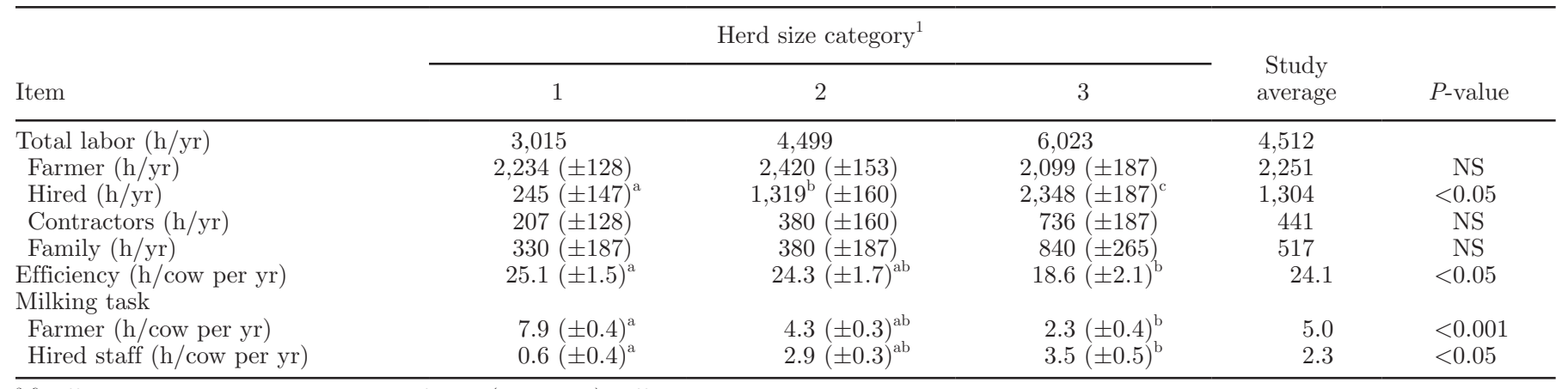

\footnotetext{
${ }^{a-c}$ Different superscripts indicate significant $(P<0.05)$ differences between herd size categories.
}

${ }^{1} 1=$ farms with $<150$ cows; $2=$ farms with 150 to 249 cows, and $3=$ farms with $\geq 250$ cows. 
ers. The proportion of time (h/cow per yr) spent at tasks across HSC by hired staff can be found in Figure 2. Hired staff had a higher proportion of their time (h/ cow per yr) dedicated to milking than any other task. As seen in Table 5, a significant drop occurred between HSC in the amount of time (h/cow per yr) farmers spent at "milking."

Within the subset of farms $(\mathrm{n}=24)$ that had a full 12 mo of data, the average herd sizes were 114 cows, 188 cows, and 305 cows for HSC 1, 2, and 3, respectively. The $25 \%$ most and least efficient farms in this group were identified as outlined previously with average herd sizes of 215 and 128 cows, respectively. Task and group task efficiency data can be found in Table 6 . With regard to labor efficiency of different tasks, "milking" and its associated tasks ("herding pre- and postmilking," and "washing post-milking") were performed significantly more efficiently in HSC 3 at $5.3 \mathrm{~h} /$ cow per yr than in HSC 1 ( $8.7 \mathrm{~h} /$ cow per yr; $P=0.006)$. Significant differences were observed between the most efficient $25 \%$ and least efficient $25 \%$ of farms for the tasks of "cow care" $(P<0.001)$ and "milking" $(P=$ $0.03)$. When examined on a more detailed task basis, the differences in "cow care" were largely attributed to the task of "winter feeding" where the most efficient $25 \%$ performed the task in $1.9 \mathrm{~h} /$ cow per yr less time than the least efficient $25 \%$. The difference in the group task of "milking" was attributed to the task of "milking" $(P<0.01)$, rather than to differences in "herding" (pre-and post-milking) or "washing post-milking." The most efficient $25 \%$ of farms were milking for $3.0 \mathrm{~h} / \mathrm{cow}$ per yr less than the least efficient $25 \%$ of farms.

Time spent at the various group tasks annually across HSC can be found in Figure 3. These data will be referred to subsequently in the following section.

\section{Seasonal Effects}

The data from the subset of farms $(\mathrm{n}=24$ farms $)$ that completed a full 12 mo of data collection were analyzed on a seasonal basis. The majority of work was performed in the spring and summer, taking up 32 and $25 \%$, respectively, of the annual total labor input. The spring had significantly more overall farm hours worked than any other season at $1,214 \mathrm{~h}(P<0.05)$. For the remainder of the year, 926,890 , and $716 \mathrm{~h}$ were worked

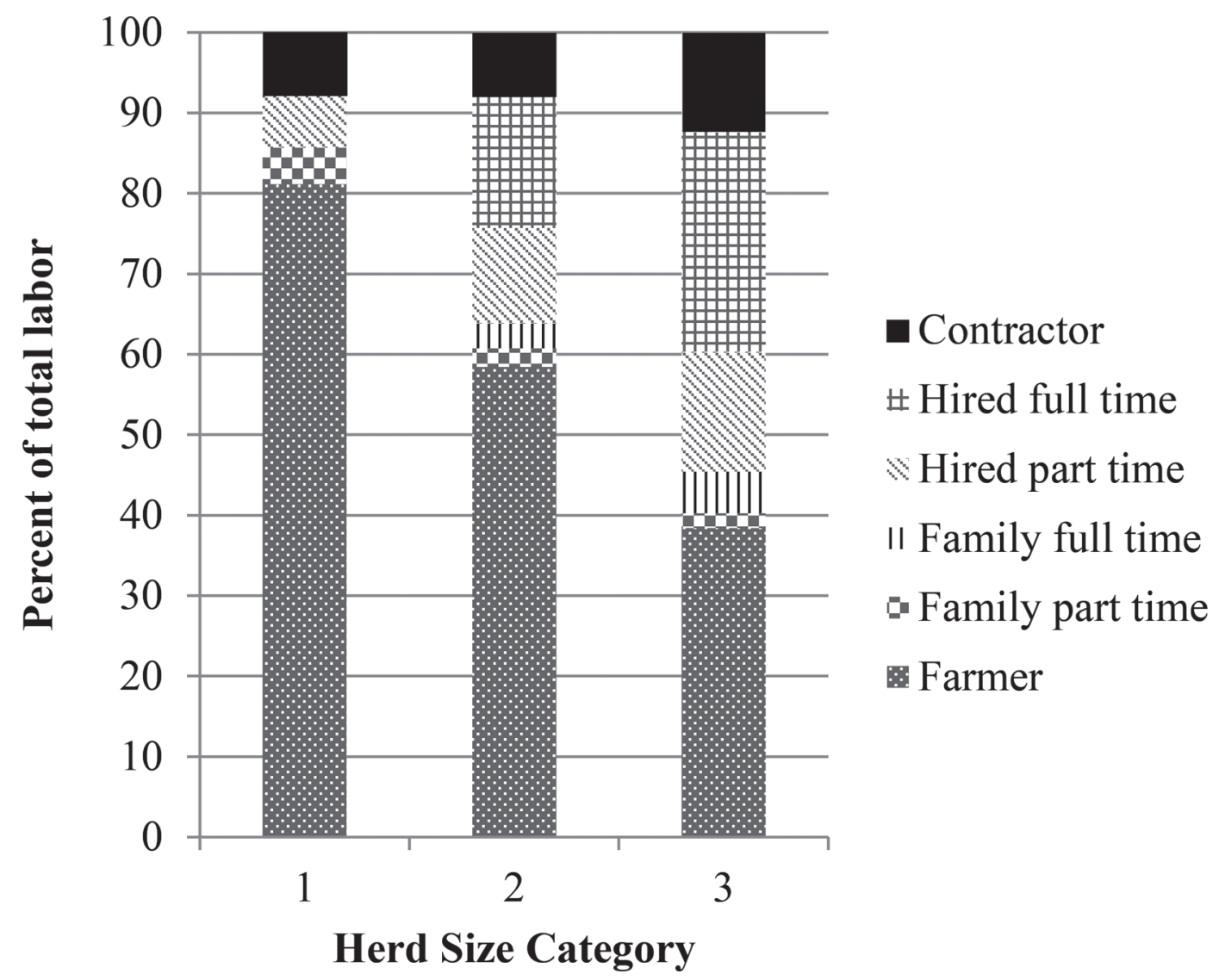

Figure 1. The average contributions of labor sources to average total farm labor consumed on farms. Herd size categories (HSC): farms with $<150$ cows (HSC 1 ), 150 to 249 cows (HSC 2 ), and $\geq 250$ cows (HSC 3 ). 


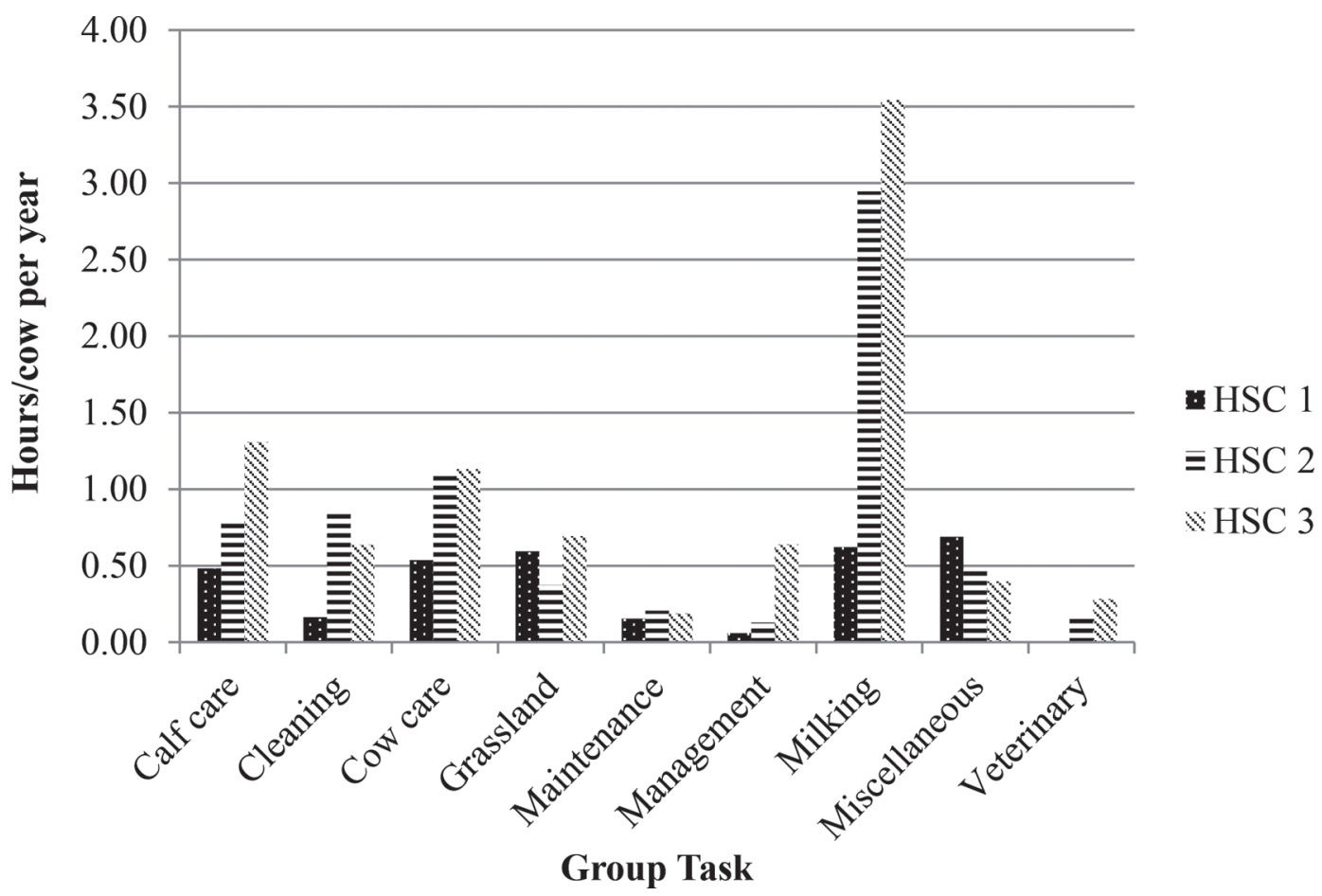

Figure 2. Proportion of time (h/cow per yr) spent at tasks by hired staff across herd size category (HSC). HSC $1=$ farms with $<150$ cows; HSC 2 = farms with 150 to 249 cows; and HSC $3=$ farms with $\geq 250$ cows.

for the summer, autumn, and winter, respectively. Labor input declined in the winter due to the seasonality of the pasture-based dairy system.

Seasonal variation in task categories is found in Figure 4. The task of "milking" (herding pre-milking and post-milking, milking, and washing post-milking) had the highest labor input on a per cow basis for 3 of the 4 seasons. "Cow care" was by far the most labordemanding group task during the winter season. Due to the fact that "milking" and "cow care" used the largest proportions of labor on an hours per cow basis in the current study, it was not surprising that they were also the categories that had the most significant differences between the $25 \%$ most efficient and least efficient farms. Information from the facilities and management phone survey were used in an attempt to explain those differences and can be found in Table 7 . With regard to the milking tasks, the most likely influencing factor was the capacity of the milking parlor and the number of cow rows being milked. A row of cows is the number of cows that are milked per session (equivalent to the number of milking units) on each side of a herringbone parlor (swing over). The more efficient farms averaged 9 rows of cows, whereas the less efficient farms averaged 11 rows. Additionally, more backing gates were present in the collecting yards of the most efficient farms group versus the least efficient farms group. A backing gate is a gate that crowds the cows toward the milking parlor and an automated backing gate can be moved from a switch in the parlor, eliminating the need for a person to physically push the cows into the milking parlor. No significant differences were observed in herds' mean SCC across HSC. Additionally, no association $(P=$ 0.62 ) was present between SCC and milking efficiency (h/cow per yr).

Both the most efficient and least efficient farms practiced similar minimal teat preparation, thus the substantially faster milking time of the most efficient farms did not negatively affect milk quality (as reflected in SCC) due to less teat preparation. All but one of the most efficient farms used once a day (OAD) milking for at least $4 \mathrm{wk}$ in the spring (beginning of lactation).

In regard to "cow care," farms in the most efficient group had an average of 3 areas in which they fed cows and heifers, whereas the least efficient farms had an average of 4 areas. Additionally, the majority of the most efficient farms delivered fresh feed every second day, whereas the least efficient farms delivered the amounts daily. The delivery of fresh feed was primarily by tractor and shear grab, tractor and finger grab, or industrial loader in the most efficient farms; feeder wagons were used only in the least efficient farms.

While "calf care" only accounted for $8 \%$ of total annual farm labor, when broken down by season, this task 
Table 6. Average hours/cow per year within tasks and groups for across herd size category and the $25 \%$ most efficient and $25 \%$ least efficient farms

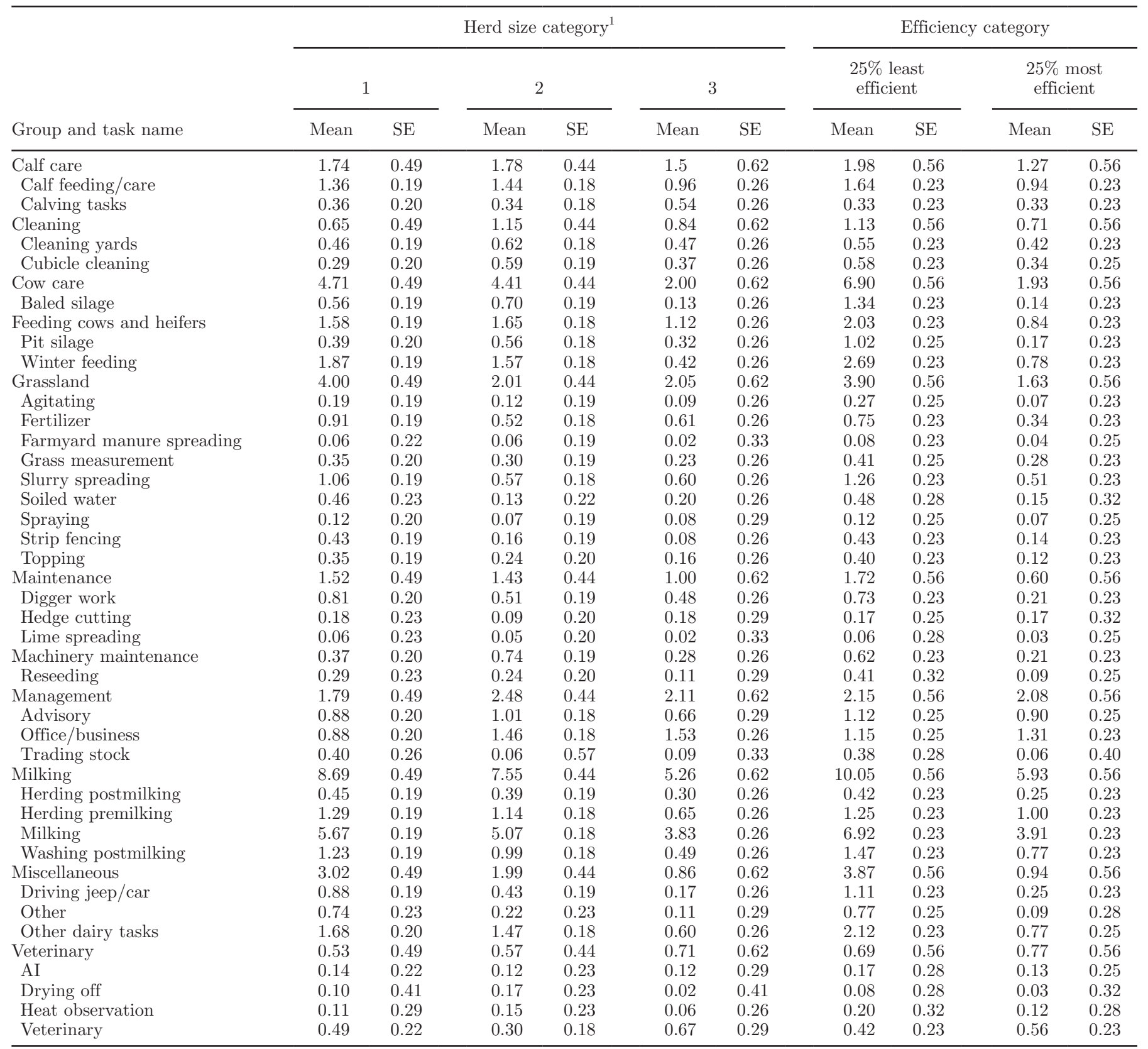

${ }^{1} 1$ = farms with $<150$ cows; $2=$ farms with 150 to 249 cows; and $3=$ farms with $\geq 250$ cows.

was the second highest consumer of labor (after "milking") in the spring season. Thirty of the 38 farms on the study reared all their calves at home. It should be noted that the measure for calf duties in the app was grouped as "calf care/feeding," and thus, it was unclear which hours were dedicated to calf care (including cleaning duties) or calf feeding separately. The average total time spent at "calf care/feeding" was $306 \mathrm{~h} / \mathrm{yr}$ across the 3 HSC. No significant differences were observed between HSC and hours spent at "calf care/feeding," but hours were 185, 319, and 473 for HSC 1, 2, and 3, respectively, as seen in Figure 3. On an hours per cow basis, no significant differences were present between the $3 \mathrm{HSC}$, with the average time contributed to "calf care/feeding" being $1.7 \mathrm{~h} /$ cow per yr. The labor input ranged from $0.63 \mathrm{~h} /$ cow per yr to $3.45 \mathrm{~h} /$ cow per yr.

Information regarding the management of calves can be found in Table 7 . When investigating the $20 \%$ most and $20 \%$ least efficient farms in regard to "calf care/feeding," the most efficient farms manually fed 


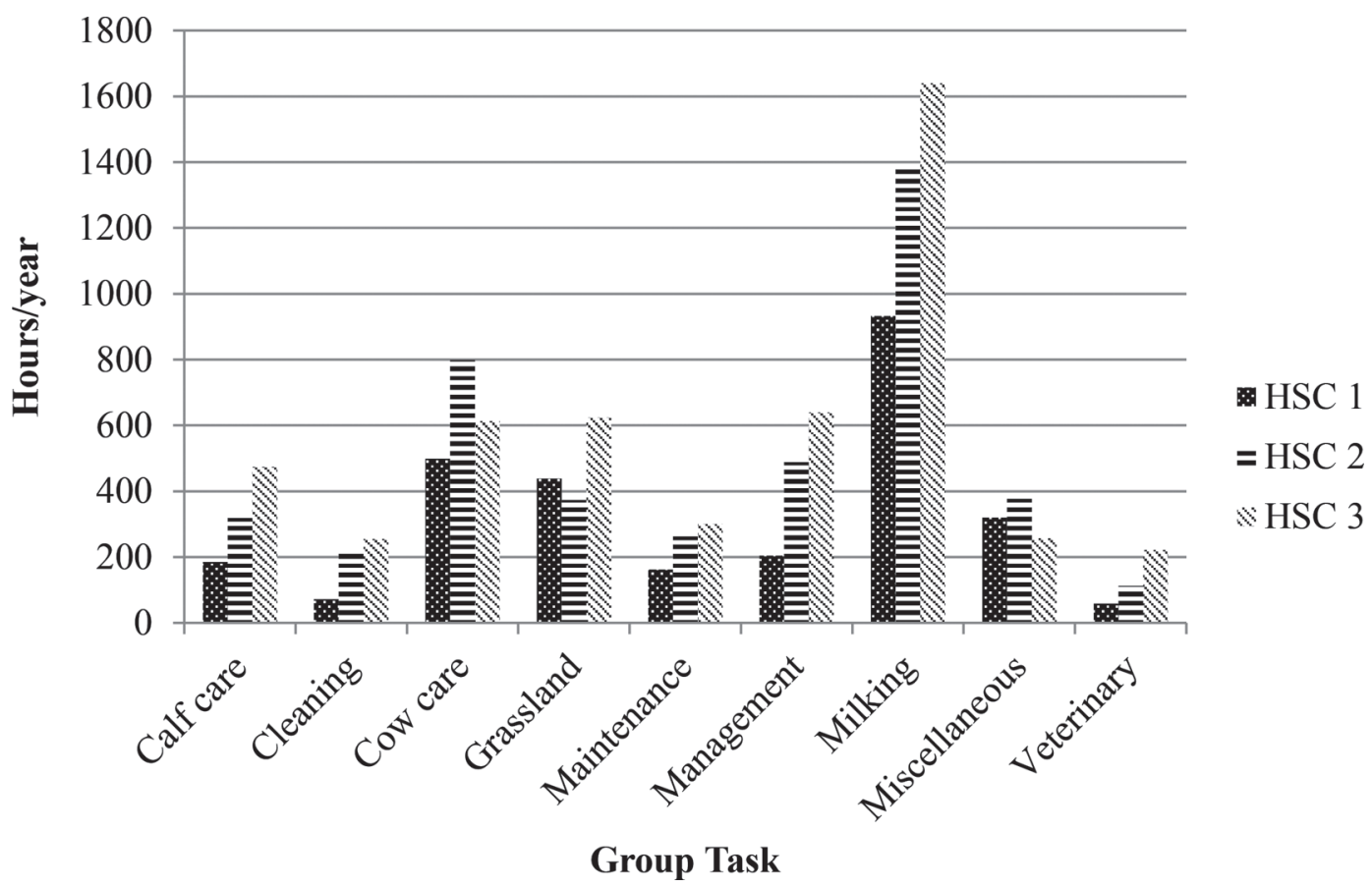

Figure 3. Time spent at the various group tasks annually across herd size categories (HSC). HSC $1=$ farms with $<150$ cows; HSC $2=$ farms with 150 to 249 cows; and HSC $3=$ farms with $\geq 250$ cows.

colostrum to all calves and the majority did so with a stomach tube. Conversely, the least efficient farms used a combination of unassisted suckling off the dam and feeding colostrum from a bucket without a teat. It should be noted that one of the top $20 \%$ efficient farms had fragmented farms (noncontiguous land plots) but half of the least efficient $20 \%$ of farms had fragmented farms and those ranged from 1.5 to $8 \mathrm{~km}$ away from the home block. The most efficient farms housed calves within a range of 5 to $400 \mathrm{~m}$ away from the milking par- lor. Conversely, the least efficient farms housed calves a range of 10 to $8 \mathrm{~km}$ away. All farms in the most efficient group fed warm fresh milk to both young and older calves, whereas the least efficient farms were feeding more milk replacer to older calves as they used automatic calf feeders. Of those farms feeding warm, fresh milk, both groups used a combination of transporting milk by hand and quad tank. A higher proportion of milk was hand drawn from the milking parlor to the calves in the more efficient farms than the least efficient

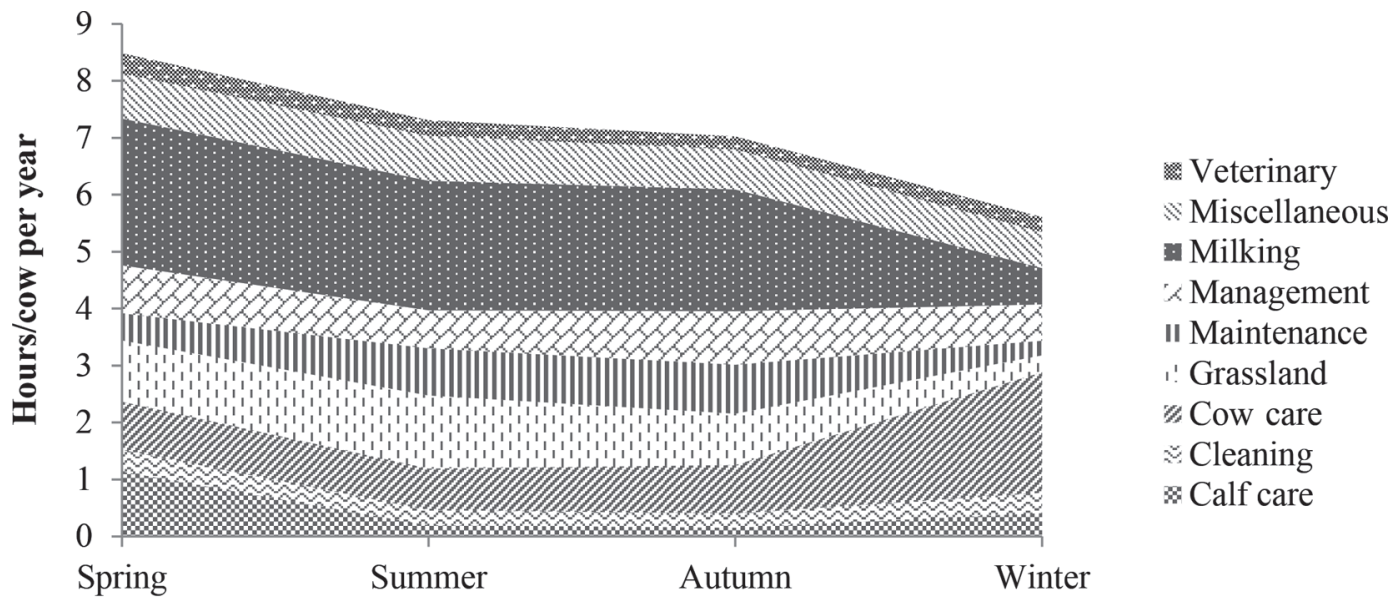

Season

Figure 4. Average labor input of group tasks by season in hours/cow per year on a subset of farms that recorded all $12 \mathrm{mo}(\mathrm{n}=24)$. 
Table 7. Descriptive characteristics of herds practicing different methods for milking, winter feeding, and calf care within the $25 \%$ most and $25 \%$ least efficient farms

\begin{tabular}{|c|c|c|}
\hline Group task & $\begin{array}{l}25 \% \text { Most efficient } \\
(\mathrm{n}=6)\end{array}$ & $\begin{array}{l}25 \% \text { Least efficient } \\
(\mathrm{n}=6)\end{array}$ \\
\hline \multicolumn{3}{|l|}{ Milking } \\
\hline Rows of cows & 9 & 11 \\
\hline Automatic backing gate present (\%) & 50 & 17 \\
\hline \multicolumn{3}{|l|}{ Cow care } \\
\hline \multicolumn{3}{|l|}{ Winter feed delivery } \\
\hline Deliver fresh feed every second day $(\%)$ & 66 & 17 \\
\hline Tractor and finger grab (\%) & 17 & 17 \\
\hline Tractor and shear grab (\%) & 50 & 33 \\
\hline Industrial loader $(\%)$ & 17 & 0 \\
\hline Feeder wagon $(\%)$ & 0 & 33 \\
\hline Ring feeder $(\%)$ & 17 & 17 \\
\hline \multicolumn{3}{|l|}{ Calf care/feeding } \\
\hline \multicolumn{3}{|l|}{ Colostrum feeding method (\%) } \\
\hline Bottle and teat & 17 & 33 \\
\hline Stomach tube & 83 & 50 \\
\hline Average distance from milking parlor to calves (m) & 94 & 1,380 \\
\hline & (range $5-400)$ & (range $10-8,000)$ \\
\hline \multicolumn{3}{|l|}{ Method of fresh milk transport (\%) } \\
\hline Hand-drawn in buckets & 47 & 40 \\
\hline Quad tank & 53 & 60 \\
\hline \multicolumn{3}{|l|}{ Type of milk fed (\%) } \\
\hline Warm fresh milk & 100 & 80 \\
\hline Warm milk replacer & 0 & 20 \\
\hline \multicolumn{3}{|l|}{ Calf-feeding method (\%) } \\
\hline Mob-feeder & 75 & 67 \\
\hline New Zealand style feeder & 25 & 17 \\
\hline Automatic feeder & 0 & 17 \\
\hline
\end{tabular}

${ }^{1} \mathrm{~A}$ farm was considered fragmented if the calves were housed $\geq 1 \mathrm{~km}$ from the main block.

${ }^{2}$ When calves are turned out to grass, this does not mean that they are weaned necessarily; it is just that they have access to grass outdoors.

${ }^{3}$ Farmers were asked if calves were housed in individual pens at some point. All farms eventually housed their calves in group pens.

farms. Both efficient and inefficient farms fed with a group "mob" feeder and New Zealand style round feeder. The least efficient farms had a higher incidence of feeding with an automatic calf feeder. Aside from the farms who fed ad libitum from an automatic calf feeder, all of the farms initially offered milk twice per day, then decreased to OAD milk feeding between 2 and 5 wk of age.

Although the farms that used the automatic calf feeders did not have to physically feed the calves, the feeders were filled with bags of milk replacer powder twice daily. Two of the most efficient farms used individual calf pens, whereas the farms in the least efficient groups all housed calves for at least $1 \mathrm{~d}$ in individual pens bed- ded with straw. The most efficient farms put calves out to grass at an average $6 \mathrm{wk}$ of age and weaned at $11 \mathrm{wk}$, whereas the least efficient farms put calves out to grass at $9 \mathrm{wk}$ of age and weaned at $10 \mathrm{wk}$ of age.

Average start and finish times of the day in the springtime and over the course of the year for the farmer can be seen in Table 8. The length of the working day (averaged over the year) for the farmer (excluding breaks and other enterprise tasks) was $7.4 \mathrm{~h} / \mathrm{d}$ for HSC $1,8.1 \mathrm{~h} / \mathrm{d}$ for HSC 2 , and $6.8 \mathrm{~h} / \mathrm{d}$ in HSC 3 . Average start times of the day during the springtime months (February, March, and April) were 0700, 0643, and $0610 \mathrm{~h}$ for HSC 1, 2, and 3 respectively. During these months, HSC 1, HSC 2, and HSC 3 finished at 1841, 
Table 8. Farmer average start time and finish time, length of the working day, and actual hours worked per day over the year and in the peak spring season

\begin{tabular}{|c|c|c|c|c|}
\hline \multirow[b]{2}{*}{ Item } & \multicolumn{3}{|c|}{ Herd size category $^{1}$} & \multirow[b]{2}{*}{$P$-value } \\
\hline & 1 & 2 & 3 & \\
\hline Start time $(\mathrm{h})$ & $0731^{\mathrm{a}}$ & $0713^{\mathrm{a}}$ & $0640^{\mathrm{b}}$ & $<0.05$ \\
\hline Finish time $(\mathrm{h})$ & $1756^{\mathrm{a}}$ & $1755^{\mathrm{a}}$ & $1527^{\mathrm{b}}$ & $<0.05$ \\
\hline Length of day (h/d) & 10.4 & 10.7 & 8.8 & \\
\hline Nonfarm activity $(\mathrm{h} / \mathrm{d})$ & 3.0 & 2.6 & 2.0 & \\
\hline Length of the day excluding nonfarm activity $(\mathrm{h} / \mathrm{d})$ & 7.4 & 8.1 & 6.8 & 0.07 \\
\hline Length of day: spring (h/d) & 11.7 & 11.8 & 11.4 & \\
\hline Nonfarm activity: spring (h/d) & 3.1 & 2.8 & 2.4 & \\
\hline Length of the day excluding nonfarm activity: spring (h/d) & 8.6 & 9.0 & 9.0 & NS \\
\hline
\end{tabular}

$\overline{\mathrm{a}, \mathrm{b}}$ Different superscripts indicate significant differences $(P<0.05)$ between herd size categories.

${ }^{1} 1=$ farms with $<150$ cows; $2=$ farms with 150 to 249 cows; and $3=$ farms with $\geq 250$ cows.

1832, and $1733 \mathrm{~h}$, respectively. During the springtime, farmers in HSC 1 worked an average of $8.6 \mathrm{~h} / \mathrm{d}$, whereas those in HSC 2 and HSC 3 were working $9.0 \mathrm{~h} / \mathrm{d}$. Seasonal variation in the length of the working week was observed for farmers across the year, with averages of $56 \mathrm{~h} /$ wk in spring (February, March, and April), 45 $\mathrm{h} /$ wk in summer (May, June, and July), $44 \mathrm{~h} /$ wk in autumn (August, September, and October), and $35 \mathrm{~h} /$ wk in winter (November, December, and January).

\section{Machinery Work}

Machinery work (performed by both the farmer/family/staff and contractors) accounted for $19.1 \%$ of total farm work across all farms. A description of machinery work is shown in Table 9. Total machinery work performed on farm increased as HSC increased. When analyzed on a per cow basis, no significant differences were present across HSC for overall machinery work. Differences were observed in the amount of work performed by the farmer/family/staff itself on an hours per cow basis, with HSC 1 relying on more of its own machinery work relative to HSC 3. A positive relationship was observed between amount of machinery work performed by contractors and level of overall farm efficiency ( $P$ $<0.01$ ) with the most efficient farms having a greater proportion of overall machinery work performed by contractors. No significant differences were observed between the $3 \mathrm{HSC}$ in terms of hours spent at various machinery tasks. In ranking by total farm efficiency, the $25 \%$ most efficient farms tended $(P=0.09)$ to use contractors for a greater proportion of total machinery work (49\%) compared with the $25 \%$ least efficient farms $(27 \%)$. The difference in efficiency of machinery tasks between the $25 \%$ most and $25 \%$ least efficient farms is shown in Figure 5. The 25\% most efficient farms spent $598 \mathrm{~h}$ at machinery tasks compared with the $25 \%$ least efficient farms that spent $1,201 \mathrm{~h}$. A large variation was present in time spent per cow on tasks within the group task of "cow care" ("baled silage," "pit silage," and "winter feeding") and on "slurry spreading" and "fertilizer spreading" in the group task of "grassland."

Table 9. Proportion $( \pm \mathrm{SE})$ of machinery work performed by the farmer/family/staff themselves or by a contractor

\begin{tabular}{|c|c|c|c|c|}
\hline \multirow[b]{2}{*}{ Item } & \multicolumn{3}{|c|}{ Herd size category $^{1}$} & \multirow[b]{2}{*}{$P$-value } \\
\hline & 1 & 2 & 3 & \\
\hline Machinery work (h) & $680^{\mathrm{a}}( \pm 95)$ & $959^{\mathrm{ab}}( \pm 113)$ & $1,128^{\mathrm{b}}( \pm 139)$ & $*$ \\
\hline Machinery work (h/cow) & $6.0( \pm 0.7)$ & $5.4( \pm 0.8)$ & $3.7( \pm 1.0)$ & NS \\
\hline Contracted $(\mathrm{h})$ & $207^{\mathrm{a}}( \pm 71)$ & $348^{\mathrm{ab}}( \pm 84)$ & $663^{\mathrm{b}}( \pm 103)$ & $*$ \\
\hline Farmer/family/staff (h) & $474( \pm 71)$ & $611( \pm 84)$ & $473( \pm 103)$ & NS \\
\hline Contracted (h/cow) & $1.7( \pm 0.5)$ & $1.9( \pm 0.6)$ & $1.9( \pm 0.8)$ & NS \\
\hline Farmer/family/staff (h/cow) & $4.3^{\mathrm{a}}( \pm 0.5)$ & $3.4^{\mathrm{ab}}( \pm 0.6)$ & $1.5^{\mathrm{b}}( \pm 0.8)$ & $*$ \\
\hline Contracted (\%) & $36( \pm 5.1)$ & $36( \pm 6.1)$ & $58( \pm 7.5)$ & NS \\
\hline Farmer/family/staff (\%) & $64( \pm 5.1)$ & $64( \pm 6.1)$ & $43( \pm 7.5)$ & NS \\
\hline
\end{tabular}




\section{DISCUSSION}

\section{On-Farm Labor Input}

It has been estimated that 15,000 additional dairyrelated jobs will be created in Ireland in the post-quota era (Teagasc, 2017). Although several of these will be associated with manufacturing and distribution sectors of the dairy processing industry (Teagasc, 2015), a portion will represent work positions on farms, either at the semi-skilled, skilled, or managerial level. This trend has been observed in the current study. Overall, as herd size increased, the amount of labor required on farm increased and that labor was increasingly supplied by hired staff. This finding was similar to the results witnessed in O'Donovan et al. (2008). A study by Blanc et al. (2008) also indicated that the proportion of hired staff on farms in developed countries has increased in recent years. Interestingly, total farmer labor hours did not vary significantly across each of the 3 HSC. It could be that farmers of small herd sizes expand the work to fill the day, whereas farmers of larger herd sizes have more hired labor to complete the tasks. Thus, it is necessary to focus on improving work organization to shorten the working day of the smaller herd size farmers and reduce the duration or members of hired labor on the larger herd size farms.

A higher level of farm labor efficiency on dairy farms was observed in the current study compared with the previously mentioned Irish studies. This was to be expected primarily because the farms in this study were chosen as labor efficient, whereas in the previous study by O'Donovan et al. (2008) farms were more representative of the overall dairy sector. A tendency toward improved efficiency as HSC increased was observed in both studies.

"Milking" and its associated tasks accounted for 33\% of total farm labor. In other pasture-based dairy studies, the proportion of overall farm labor dedicated to milking has ranged from 32 to $57 \%$ (Mein and Smolenaars, 2001; O'Donovan et al., 2008; Taylor et al., 2009). The task of "milking" was the largest reason for hired staff requirements; this was clearly highlighted by the increased proportion of milking being conducted by hired staff (and reduced proportion conducted by the farmer) as herd size increased. The most efficient farms were saving, on average, $3 \mathrm{~h} / \mathrm{cow}$ per yr on the task of "milking," compared with the least efficient, which could be a significant savings for both small farms and large farms alike.

While one of the factors affecting milking time is the rate at which individual cows can be milked, another variable is the capacity of the milking parlor (O'Brien et al., 2012). The swing-over herringbone milking parlor is the most common style of milking parlor in the pasturebased systems in Ireland (91\%) and New Zealand (72\%; Kelly, 2009; Edwards et al., 2015) and is popular for its low investment costs. The number of milking units in the parlor and thus number of rows of cows that are milked can affect the overall milking time (O'Brien et al., 2012; Edwards et al., 2013b). The results from the current study reiterate findings from a previous Irish

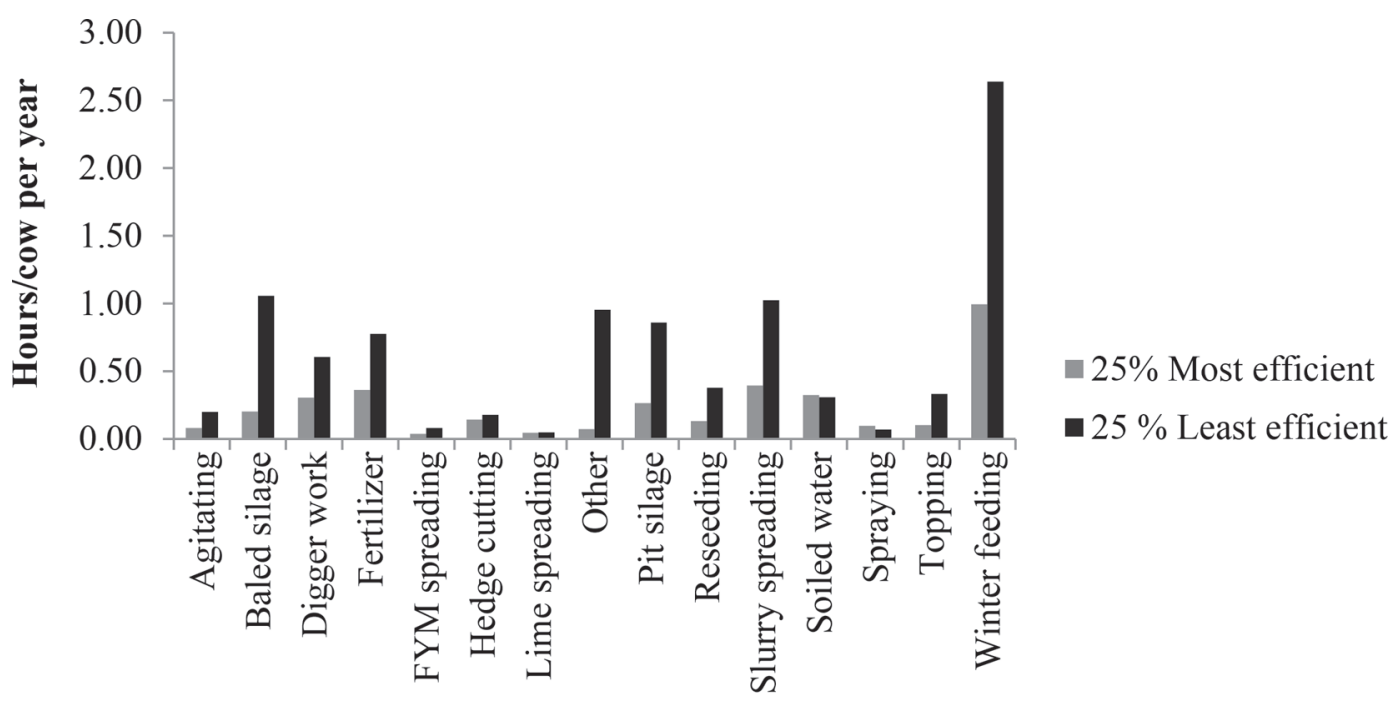

Machinery Task

Figure 5. Difference in proportion of time spent at machinery tasks between the $25 \%$ most and $25 \%$ least efficient farms. FYM $=$ farm yard manure. 
labor study, which found that fewer rows of cows was more prevalent in the most efficient farms (O'Brien et al., 2006b). Whereas overall milking time may be reduced with an increased number of clusters, this will only occur while the operator still has some idle time. Once idle time has been eliminated, further increase in unit number will not increase cow throughput. Having a backing gate to help herd the cows into the parlor is one labor-saving technology (Fox, 1994), which was witnessed on the higher efficiency farms in the current study. Various New Zealand studies have focused on milking management and have identified technologies such as teat sprayers, cup removers, and auto-drafting on larger dairy herds. Participants in the studies noted that the main reasons they invested in technology on farm was to reduce labor requirements, make milking easier, and attract/retain staff (Jago et al., 2011; Edwards et al., 2013a; Eastwood et al., 2015). A study by Eastwood et al. (2015) indicated that farmers reported overall satisfaction with technology adoption and that they would implement them again if given the chance; however, some users ran into difficulties with inaccurate data collection, lack of post-implementation support, and technical issues. This needs to be taken into account together with studies on potential time/labor saving technologies to assist appropriate technology application on Irish dairy farms.

High labor demands in the spring resulting from the seasonal calving, "milking" tasks, and "calf care/feeding" tasks can be offset by changing to OAD milking in the busy spring period. Once a day milking has the potential to reduce income (O'Brien et al., 2006a), but this may be outweighed by increased labor flexibility and overall reduced labor and demand. Additionally, it was identified by Clarke et al. (2006) as a way to improve lifestyle for farm families and staff. The practice of milking $\mathrm{OAD}$ in early lactation was one of the contributing factors to increased labor efficiency for the milking task. Therefore, it is recommended that farmers consider this practice as an option to reduce labor demand around the milking task.

After "milking," the group task of "cow care" accounted for a large portion of annual labor. Hours spent at baled silage and pit silage, in addition to winter feeding, contributed to the high number of hours required in the "cow care" group task. Although most Irish farms operate the grass-based system, cows are housed indoors during the winter months and, thus, harvested feed must be delivered to them. The most efficient farms were not only spending fewer hours performing all of these tasks but doing so for a larger number of animals. This could be attributed to contractors performing the tasks more efficiently with larger equipment or better farm layout on the more efficient farms. Additionally, although measurements of the feed-bunk face were not recorded, the more efficient farms had an overall reduced labor demand for winter feeding, which may have been attributed to larger feed-bunk faces allowing for fresh feed delivery every second day (rather than daily). Increased use of shear grab and industrial loaders may also have contributed to the reduced feeding time. Further research in this area with a focus on economics would be beneficial in determining if equipment investment would be advantageous for farms based on the labor savings found in this study. Additionally, the finding regarding contractor use being more prevalent on the more efficient farms may represent another area for future research to help identify where the efficient use of contractors becomes cost effective.

The calf-care task is also significant in grass-based dairy systems due to the seasonality of the herd calving event. In regard to "calf care/feeding," the current study reflected similar results to those witnessed in a past pasture-based dairy farm labor study (Gleeson et al., 2007) where they found that labor demand for calf rearing increased as herd size increased; labor efficiency was not significantly improved with the increase in herd size. This can be influenced by more individual rather than group management of calves. Some unexpected but explainable situations were also observed. The factor of farm fragmentation has an effect on time spent at calf care. The higher incidence of the seemingly less efficient method of warm milk transfer to the calves in the most efficient group is likely explained by the close proximity of calves to the milking parlor in comparison to the distance milk needs to be transported on the fragmented, less efficient farms. Also, although automatic calf feeders represent new technology adopted by farmers with the intention of easing the calf feeding task labor requirements (Medrano-Galarza et al., 2016), farms likely keep their calves indoors for longer periods of time to make the most of their investment and because it is a simple way of feeding calves. On the other hand, when calves are housed indoors there is the associated higher labor requirement to clean out wet group-housed pens (Gleeson et al., 2007). In that study, the most efficient farms turned the calves out to grass earlier, which likely reduced the amount of time spent at cleaning pens.

Although all of the farms in the study initially fed calves twice per day, they decreased to once daily milk feeding subsequently. A higher labor requirement is associated with twice daily milk feeding (Gleeson et al., 2008), and because past studies did not find adverse effects of once daily milk feeding on calf performance, this is a recommended labor-saving strategy in Ireland (Fallon et al., 1985; Williams et al., 1986; Gleeson et al., 2007). 


\section{Machinery Work}

While there is a dearth of empirical data on the use of contractors for various machinery tasks on pasturebased farms, this study indicates that farmers have the potential to reduce their personal work load and own farm machinery depreciation through the use of contractors. A study by Errington (1998) highlighted the growth of utilizing agricultural contractors in the United Kingdom for reasons such as alleviating labor demands and managing the farm's labor force during the seasonal peaks and troughs. Machinery work accounted for approximately $20 \%$ of all farm labor across the 3 HSC in this study and all of those machinery tasks have the potential to be outsourced to contractors. When considering work-life balance, utilizing contractors, especially in the springtime, can alleviate some of the work load during this stressful period. Considerable differences were observed between the hours per cow spent at the machinery tasks between the $25 \%$ most efficient and $25 \%$ least efficient farms. The $25 \%$ least efficient farms spent more than twice the number of hours on machinery tasks compared with the $25 \%$ most efficient farms. Thus, it would be important to focus on this potential to decrease machinery work hours on farms, together with the economic aspect of this practice.

\section{Seasonal Aspect to Labor Requirements On-Farm}

In addition to examining which tasks were the most time consuming over the course of the year across the $3 \mathrm{HSC}$ in terms of the hours/cow per year, these tasks were also examined in terms of season, which is especially important in a seasonal dairying system. Anecdotally, the highest amount of pressure and stress that pasture-based farmers undergo is in the springtime season due to calving and calf care responsibilities. By season, as to be expected, "milking," "cow care," and "calf care" were consistently the most labor-intensive tasks on farm. The study herds were spring-calving with the tasks of "calving" and "milking" commencing, while "cow care" (feeding of cows indoors) still continued. Thus it is important to put particular focus on identifying labor-saving techniques of the farms most efficient in those tasks during the critical high labor input seasons (e.g., OAD milking, OAD feeding of calves, and contract feeding of cows).

\section{Farmer Hours}

The main farm operators in HSC 3 finished their days significantly earlier than the farmers on smaller farms (HSC 1 and 2); primarily due to more hired staff on farm performing the evening milking. The HSC 3 farmers had not only the shortest annual average day from start to finish but also had the least nonfarm activity, indicating they dedicated more of their working day to actual farm work with the ability to finish the day earlier.

The reasonable start and finish times and length of the working day of farmers on this study, both throughout the year and during the peak season, are encouraging. Farming previously set itself apart from other occupations in terms of long, unsociable hours (Ní Laoire, 2002). Some evidence indicates that members of the younger generation are choosing occupations outside of dairy farming, which may be influenced by policies and poor land mobility. Studies have indicated that young farmers are placing more emphasis on the desire for a better work-life balance (Brandth and Overrein, 2013), and thus, improving farmer work and labor efficiency hours may help to attract young people to continue the next generation of farming.

As mentioned previously, the only statistical differences in the proportion of hired staff performing different tasks between HSC was observed for the task of "milking"; however, some interesting conclusions may be drawn from the task data in relation to hired staff. The amount of time (h/cow per yr) dedicated to "management" by hired staff was small in comparison to other tasks they performed. This is in agreement with current knowledge on an increase in demand for hired staff to perform "milking," "calf care," and "cow care" as herd sizes increase. Thus, it may be beneficial to place more focus on training of staff in these tasks, rather than for higher level managerial work.

\section{Reflection on Research Method, Limitations, and Future Research}

Although there were some obstacles with using an app for the data collection of labor, overall it was considered a streamlined and efficient method due to the frequent everyday use of the smartphone. Additionally, the inputting of data "live" by the farmers allowed the researcher to remotely monitor and consult the farmers regarding correction of the data if necessary.

Some limitations were associated with the study. Due to the detailed attention required for data recording, the study was limited to collection of data on $3 \mathrm{~d}$ per month during the middle of the week. To keep data collection as simple and repetitive as possible, users collected data on the same days each month rather than changing or staggering the days of data collection, thus weekends were not included. However, work performed on the weekends is generally limited to only the necessary tasks such as milking and feeding (O'Donovan, 2008). In addition to the work performed potentially 
being different, there was a chance that the people performing the work on the weekends was not captured as it would not be uncommon for college-aged children to return to work on the farm over the weekends. If the study were to be performed again, conducting a piloting phase of the app with the farmers would be beneficial to ensure complete data sets from the commencement of the actual study.

This study highlighted where opportunities exist for future research in this field. The relatively large differences between the most and least efficient farms could be further investigated in terms of work organization and facilities. More research dedicated to the machinery tasks, farm layout, and the use of contractors would be beneficial to the industry.

\section{CONCLUSIONS}

The objective of this paper was to quantify labor input on labor-efficient dairy farms of varying sizes in Ireland. This study had 5 major findings. The first was that as herd size increased above 250 cows, labor efficiency improved significantly. However, the data also showed a large range of labor efficiency within each HSC, showing that even farms in the smallest HSC were capable of achieving high levels of efficiency. Next, the results indicated that while farmer hours remained relatively consistent across different herd sizes, the average length of the working day is competitive with other vocations, which may help to make dairy farming an attractive career option for the next generation. In this sense, knowledge transfer of how to achieve a reasonable work/life balance with improved efficiency is important. The proportion of overall farm labor contributed by hired staff increased significantly as herd size increased with a demand on the milking task in particular. Next, the labor requirement on farm and the tasks involved were highly seasonal with the peak being witnessed in the spring months and a particular emphasis on the group tasks of calf care, milking, and cow care. Finally, 2 of the major contributors to labor efficiency are the management practices and facilities in place on farm. This was witnessed through farmers utilizing various technologies on farm and hiring contractors to perform certain machinery tasks.

\section{ACKNOWLEDGMENTS}

The authors acknowledge the participation and cooperation of the farmers during the collection of the on-farm labor data. This research was funded by Dairy Research Ireland (Merrion Square, Dublin, Ireland) and the Teagasc Walsh Fellowship (Oak Park, County Carlow, Ireland).

\section{REFERENCES}

Blanc, M., E. Cahuzac, B. Elyakime, and G. Tahar. 2008. Demand for on-farm permanent hired labour in family holdings. Eur. Rev. Agric. Econ. 35:493-518.

Boyle, G. E. 2002. The Competitiveness of Irish Agriculture, Report for Department of Agriculture and Food, Government of Ireland. Irish Farmers Journal, Bluebell, Dublin, Ireland.

Brandth, B., and G. Overrein. 2013. Resourcing children in a changing rural context: Fathering and farm succession in two generations of farmers. Sociol. Ruralis 53:95-111.

Clarke, D., C. V. C. Phyn, M. J. Tong, S. J. Collis, and D. E. Dalley 2006. A systems comparison of once- versus twice daily milking of pastured dairy cows. J. Dairy Sci. 89:1854-1862.

CSO (Central Statistics Office). 2013. Farm Structures Survey 2013 Cork, Ireland. Accessed Dec. 1, 2017. https://www.cso.ie/en/ releasesandpublications/ep/p-fss/farmstructuresurvey2013/ detailedanalysis/farmownershipandlabourinput/.

Dairy Australia. 2015. Australian Dairy Industry In Focus 2015. Victoria, Australia

Dairy Australia. 2017. Australian Dairy Industry In Focus 2017. Victoria, Australia.

DairyNZ and Livestock Improvement Corporation (LIC). 2015. New Zealand Dairy Statistics 2014-15. LIC and DairyNZ, Hamilton, New Zealand.

DairyNZ and Livestock Improvement Corporation (LIC). 2016. New Zealand Dairy Statistics. https://www.dairynz.co.nz/media/ 5416078/nz-dairy-statistics-2015-16.pdf.

Deming, J., D. E. Gleeson, T. O'Dwyer, J. Kinsella, and B. O'Brien. 2017. Benchmarking labour input on Irish dairy farms with use of a smartphone app. Chem. Eng. Trans. 58:133-138.

Deming, J. A., T. O'Dwyer, P. Clarke, D. Gleeson, A. Renwick, and B. O'Brien. 2015. Current status of overall labor input on Irish dairy farms. Pages 35-38 in XXXVI CIOSTA \& CIGR Section V Conference. St. Petersburg, Russia. St. Petersburg State Agrarian University, St. Petersburg, Russia.

Eastwood, C., and I. Yule. 2015. Challenges and opportunities for precision dairy farming in New Zealand. Farm Policy J. 12:33-41.

Eastwood, C., B. Dela Rue, and M. Neal. 2015. Advancing your management through technology-Options from near and far. Pages 108-116 in Proceedings from South Island Dairy Event. Lincoln, New Zealand. Lincoln University, Christchurch, New Zealand.

Edwards, J. P., B. T. Dela Rue, and J. G. Jago. 2015. Evaluating rates of technology adoption and milking practices on New Zealand dairy farms. Anim. Prod. Sci. 55:702-709.

Edwards, J. P., J. G. Jago, and N. Lopez-Villalobos. 2013a. Milking efficiency can be improved by increasing automatic cluster remover thresholds to grazing dairy cows without applying pre-milking stimulation. J. Dairy Sci. 96:3766-3773.

Edwards, J. P., B. O'Brien, N. Lopez-Villalobos, and J. G. Jago. 2013b. Milking efficiency of swingover herringbone parlours in pasture-based dairy systems. J. Dairy Res. 80:467-474.

Errington, A. 1998. The increasing flexibility of machinery and labour inputs to UK farming. Etudes et Recherches sur les Sytèmes Agraires et le Développement 31:371-385.

European Commission. 2010. Europe 2020 Flagship Initiative Innovation Union COM. 546 final. Publications Office of the European Union, Luxembourg.

FADN. 2016. European Commission. Brussels May 2016. http://ec .europa.eu/agriculture/rica/pdf/Dairy_report_2015.pdf

Fallon, R. J., J. M. Brockway, and P. E. V. Williams. 1985. The effect of the frequency of feeding of milk on the energetic efficiency of pre-ruminant calves. Anim. Prod. 50:570. (Abstr.)

Faure, G., Y. Desjeaux, and P. Gasselin. 2012. New challenges in agricultural advisory services from a research perspective: A literature review, synthesis and research agenda. J. Agric. Educ. Ext. 18:461-492.

Fox, J. 1994. NZ Dairy Farmers' 111 Ideas to Improve Milking. Fox Publications, Hamilton, New Zealand.

Gleeson, D., B. O'Brien, and R. J. Fallon. 2007. Feeding of cold whole milk once daily to calves in a group and its effect on calf per- 
formance, health and labour input. Int. J. Appl. Res. Vet. Med. 5:97-104.

Gleeson, D., B. O'Brien, and K. O'Donovan. 2008. The labor input associated with calf care on Irish dairy farms. Livest. Sci. 116:82-89.

IFCN (International Farm Comparison Network). 2002. Dairy Report. International Farm Comparison Network. www.ifcndairy.org.

Jago, J., P. Edwards, and S. Scott. 2011. Milking effectively in rotary dairies. In Proceedings of the South Island Dairy Event (SIDE), 27-29 June, Lincoln University.

Jago, J. G., J. K. Burke, and J. H. Williamson. 2010. Effect of automatic cluster remover settings on production, udder health, and milking duration. J. Dairy Sci. 93:2541-2549.

Kelly, P. T. 2009. A study of the somatic cell count (SCC) of Irish milk from herd management and environmental perspectives. PhD Thesis. National University of Ireland, Dublin, Ireland.

Macken-Walsh, A., and A. Byrne. 2015. Cooperation in Irish family farming. In Family Farming in Ireland: Continuity and Change. D. Meredith, ed. Royal Irish Academy, Dublin, Ireland.

McNab, W. B., and A. H. Meek. 1991. A benefit cost analysis of dry-cow mastitis therapy in Ontario dairy herds. Can. Vet. J. 32:347-353.

Medrano-Galarza, C., J. Rushen, A. M. de Passillé, A. Jones-Bitton, T. J. DeVries, S. J. LeBlanc, and D. B. Haley. 2016. 1233 A survey of management practices and producers' perceptions regarding manual and automated milk feeding systems for dairy calves. J. Anim. Sci. 94(E-Suppl 5):593-594. (Abstr.)

Mein, G., and F. Smolenaars. 2001. Making the most of the milk harvest. A prospectus for the milk quality and harvesting program. Dairy Research and Development Corporation, Melbourne, Victoria, Australia.

Myles, L. 2000. Submission to Agrifood 2010. Farm Apprenticeship Board. Department of Agriculture, Food \& Rural Development, Dublin, Ireland.

National Farm Survey (NFS). 2016. Teagasc National Farm Survey 2015 Results. Teagasc, Athenry Ireland. Accessed Dec. 1, 2017. https://www.teagasc.ie/media/website/publications/2016/Income -Estimates-2015.pdf.

Ní Laoire, C. 2002. Young farmers, masculinities and change in rural Ireland. Ir. Geogr. 35:16-27.

O'Brien, B., J. G. Jago, J. P. Edwards, N. Lopez-Villalobos, and F. McCoy. 2012. Milking parlour size, pre-milking routine and stage of lactation affect efficiency of milking in single-operator herringbone parlours. J. Dairy Res. 79:216-223.

O'Brien, B., K. O'Donovan, D. Gleeson, D. J. Ruane, and J. Kinsella. 2006b. Improving labour productivity to facilitate viability on smaller Irish dairy farms. J. Int. Farm Manage. 3:19-37.

O'Brien, B., L. Shalloo, S. O'Donnell, A. M. Butler, D. Gleeson, and K. O'Donovan. 2006a. Labour and economic aspects of dairy farming. Page 256 in Proceedings from 57th Annual Meeting of the
European Association for Animal Production. Antalya, Turkey. Wageningen Academic Publishers, Wageningen, the Netherlands.

O'Donovan, K. 2008. Labour efficiency on Irish dairy farms. PhD Thesis. School of Agriculture and Food Science, University College Dublin, Dublin, Ireland.

O'Donovan, K., B. O'Brien, D. J. Ruane, J. Kinsella, and D. Gleeson. 2008. Labour input on Irish dairy farms and the effect of scale and seasonality. J. Farm Manage. 13.

O'Shea, J., A. J. Kavanagh, and P. Reid. 1988. Labour use on Irish dairy farms. Irish Grassland and Anim. Prod. Assoc. J. 22:112120

Porter, J. C. 1993. What dairy employees think about their jobs. J. Dairy Sci. 76:2065-2068.

Rivera, W. M. 2011. Public sector agricultural extension system reform and the challenges ahead. J. Agric. Educ. Ext. 17:165-180.

Schukken, Y. H., D. J. Wilson, F. Welcome, L. Garrison-Tikofsky, and R. N. Gonzalez. 2003. Monitoring udder health and milk quality using somatic cell counts. Vet. Res. 34:579-596.

Shortall, J., L. Shalloo, C. Foley, R. D. Sleator, and B. O'Brien. 2016. Investment appraisal of automatic milking and conventional milking technologies in a pasture-based dairy system. J. Dairy Sci. 99:7700-7713.

Taylor, G., L. van der Sande, and R. Douglas. 2009. Smarter not harder: Improving labour productivity in the primary sector. Accessed Dec. 1, 2017. http://maxa.maf.govt.nz/sff/about-projects/ search/05-028/technical-report.pdf.

Teagasc. 2015. The End of the Quota Era: A History of the Dairy Sector and Its Future Prospects. T. Donnellan, T. Hennessy, and F. Thorne, ed. Athenry, Ireland.

Teagasc. 2017. The People in Dairy Project: A report on the future people requirements of Irish dairy farming to support sustainable and profitable dairy expansion. Accessed Dec. 1, 2017. https:// www.teagasc.ie/publications/2017/the-people-in-dairy-project .php.

van Schaik, G., M. Lotem, and Y. H. Schukken. 2002. Trends in somatic cell counts, bacterial counts, and antibiotic residue violations in New York State during 1999-2000. J. Dairy Sci. 85:782-789.

Williams, P. E. V., R. J. Fallon, and J. M. Brockway. 1986. The effect of frequency of feeding milk replacer to preruminant calves on respiratory quotient and the efficiency of food utilization. Anim. Prod. 43:367-375.

Wilson, P. 2011. Decomposing variation in dairy profitability: The impact of output, inputs, prices, labour and management. J. Agric. Sci. 149:507-517.

Winsten, J. R., C. D. Kerchner, A. Richardson, A. Lichau, and J. M. Hyman. 2010. Trends in the Northeast dairy industry: Large-scale modern confinement feeding and management-intensive grazing. J. Dairy Sci. 93:1759-1769. 